\title{
Shorter Axis of Placenta
}

National Cancer Institute

\section{Source}

National Cancer Institute. Shorter Axis of Placenta. NCI Thesaurus. Code C117341.

The length, in $\mathrm{cm}$, of the shortest axis of the chorionic disc. 